\title{
Lack of Association of Mouse Mammary Tumor Virus-Like Sequences in Iranian Breast Cancer Patients
}

\author{
Mohmmad Motamedifar $^{a}$ b Morteza Saki $^{b} \quad$ Abbas Ghaderi $^{c}$ \\ ${ }^{a}$ Shiraz HIV/Aids Research Center (SHARC), bepartment of Bacteriology and Virology, Shiraz Medical School, and \\ 'Shiraz Institute for Cancer Research (ICR) and Department of Immunology, Shiraz University of Medical Sciences, \\ Shiraz, Iran
}

\section{Key Words}

Mouse mammary tumor virus • Breast cancer patients •

Shiraz • Iran

\begin{abstract}
Objective: The present study aimed to detect mouse mammary tumor virus (MMTV)-like sequences in Iranian breast cancer patients in the city of Shiraz, located in southwest Iran. Subjects and Methods: We searched for two MMTV genetic regions in the peripheral blood leukocytes of 300 women with breast cancer, 300 age-matched healthy control subjects, and 50 breast tumor tissues. Two regions of MMTV, $660 \mathrm{bp}$ and $250 \mathrm{bp}$, were searched by nested polymerase chain reactions. Results: None of the above two regions were detected. There were no differences between the control group and the breast cancer group. Conclusion: Our findings did not show any association of MMTV-like sequences with breast cancer development in Iranian patients in Shiraz.

Copyright $\odot 2011$ S. Karger AG, Basel
\end{abstract}

(C) 2011 S. Karger AG, Basel

$1011-7571 / 12 / 0213-0244 \$ 38.00 / 0$

Fax +4161306 1234

E-Mail karger@karger.ch

www.karger.com
Accessible online at: www.karger.com/mpp

\section{Introduction}

Among known risk factors for development of breast cancer, it has been suggested that an infectious agent may be one [1]. A great deal of effort has been invested in searching for a tumor virus associated with human breast cancer, yet the existence of such a virus, which has been postulated for many years, has not yet been proven.

The mouse mammary tumor virus (MMTV) is undoubtedly the major etiological agent of breast cancer in laboratory mice $[1,2]$ and, as such, has been the retrovirus most extensively searched for in human breast tumor development. MMTV, a non-acute transforming type B retrovirus, was first identified in the milk of breast-feeding mice by Bittner [3]. A mandatory step in the replication of MMTV is the integration of a DNA copy of its proviral genome into the host cellular genome, an event that is potentially mutagenic for the host cell. Although a large body of evidence for MMTV involvement in human breast tumors has been reported [4-11], such reports have often lacked verification from other laboratories and thus have led to much controversy in this field. In addition, the 
presence of human endogenous retrovirus (HERV) sequences in the human genome, which are homologous to MMTV $[12,13]$, has made it difficult to distinguish endogenous from exogenous MMTV-like sequences. Wang et al. [14] compared the sequences of the MMTV env gene with the sequences of the HERV-k10 env gene and localized a region of $660 \mathrm{bp}$ of low homology (16\%) between MMTV env nucleotides 976-1640. They then searched for sequences homologous to it using polymerase chain reaction and found that an MMTV env gene-like sequence that is $90-98 \%$ homologous to the env gene of the MMTV was present in $38 \%$ of breast cancer samples but not in normal tissues [14]. Researchers [15] therefore suggested that a related virus, called human mammary tumor virus (HMTV) with 85-95\% homology to MMTV, may be involved in human breast cancer [15]. Intrigued by this suggestion of MMTV involvement in human breast cancer, we attempted to detect these MMTV-like sequences in Iranian breast cancer patients.

\section{Subjects and Methods}

\section{Specimens and Samples}

In this cross-sectional study, DNA samples of peripheral blood of 300 women with breast cancer (mean age: $49.1 \pm 11.5$ years), and 300 age-matched healthy controls, extracted by the saltingout method, were taken at the Shiraz Institute for Cancer Research for detection of MMTV-like env gene sequences in this study. All patients were recruited during the period from 2005 to 2008 at the Breast Clinic, Shiraz Medical School, Shiraz, Iran. The breast cancer cases included 241 invasive ductal carcinoma (IDC), 19 medullary carcinoma (MC) and 40 non-well-differentiated breast cancers. All patients and controls originated from Shiraz, southwest of Iran. Breast cancer was proved from surgical and pathological reports. Controls did not have any evidence of malignancy or autoimmunity.

Also, 50 paraffin-embedded sections of breast tumor specimens from the above-mentioned patients operated at the Faghihi Hospital, Shiraz Iran, were collected from the Department of $\mathrm{Pa}$ thology, Shiraz Medical School, Shiraz, Iran. DNA samples of the peripheral blood of the same patients were obtained as well. The protocol was approved by the Ethics Committee of the Shiraz University of Medical Sciences.

\section{DNA Extraction and PCR}

DNA of paraffin-embedded sections was isolated using DNA extraction system I (Vienna Lab, Labordiagnostika gmbH, Vienna, Austria). Briefly, nuclei were lysed with SDS and proteinase $\mathrm{k}$, proteins were precipitated by addition of saturated $\mathrm{NaCl}$ solution and DNA was recovered by ethanol precipitation. High molecular weight DNA was spooled on plastic inoculation loops, dissolved in TE buffer (10 mM Tris-Hcl ( $\mathrm{pH} 7.4), 1 \mathrm{mM} \mathrm{Na}_{2}$ EDTA) and stored at $-80^{\circ} \mathrm{C}$.

Lack of MMTV Sequences in Iranian

Breast Cancer Patients
PCR was performed in $25 \mu \mathrm{l}$ reactions containing $1 \mu \mathrm{l}$ DNA plus $0.6 \mu$ l of each MMTV 660 bp env gene-like sequence primers 1N (5'-CCTCACTGCCAGATCGCCT-3'; nucleotides 976-993 of the MMTV env gene; Wang et al. [15]) and 3N (5'-ATCTGTGGCATACCTAAAGG-3'; nucleotides 1640-1621 of the MMTV env gene; Wang et al. [15]), $1 \mu \mathrm{l}$ of $\beta$ globin primers (BF: $5^{\prime}-$ ACACAACTGTGTTCACTAGC-3' and BR: 5'-CAACTTCATCCACGTTCACC-3') as the internal control [16], $0.7 \mu l$ dNTPs, $2.5 \mu \mathrm{l} 10$-fold buffer, $2 \mu \mathrm{l}$ Taq polymerase, $0.65 \mu \mathrm{l} \mathrm{MgCl}_{2}$, and $4.95 \mu$ l distilled water (Aqua dest, $\mathrm{GmbH}$, Germany). To detect possible contamination of the master mix components, a control lacking DNA was routinely included. Thermocycling was performed by denaturation at $94^{\circ} \mathrm{C}$ for $5 \mathrm{~min}$, followed by 35 cycles of $94^{\circ} \mathrm{C}$ for $30 \mathrm{~s}, 60^{\circ} \mathrm{C}$ for $30 \mathrm{~s}$, and $72^{\circ} \mathrm{C}$ for $30 \mathrm{~s}$.

The product of the PCR was analyzed by electrophoresis in a $2 \%$ agarose gel with ethidium bromide staining. A sequence of the cloned env gene that was obtained from the American Type Culture Collection (ATCC No. 45006, p 203) was used as a positive probe to determine optimal $\mathrm{Mg}^{2}$ primer concentrations and requirements for the different cycling temperatures. To detect possible contamination of the master mix components, a control lacking DNA was routinely included. A pUC19/Mspl DNA ladder was used to identify the size of the PCR products.

Detection of MMTV 250 bp env gene-like sequence in DNA of paraffin-embedded sections and peripheral blood used nested PCR. In our study, to maximize the sensitivity and specificity, we analyzed human breast tumors for the presence of the $250 \mathrm{bp}$ sequence fragment after nested PCR reactions. Screening of this 250 bp fragment was performed with two sets of primers: MMTV2 (5'-TACATCTGCCTGTGTTAC-3'; nucleotides 13881405 of the MMTV env gene 917) and MMTV3 (5'-ATCTGTGGCATACCT-3'; nucleotides 1640-1626 of the MMTV env gene [17]).

For the nested PCR round, $1 \mu$ l of the product of the first PCR was added to a reaction volume of $25 \mu \mathrm{l}$ containing $0.6 \mu \mathrm{l}$ of each MMTV 250 bp env gene-like sequence primers, $1 \mu$ l of $\beta$ globin primers as internal control, $0.7 \mu \mathrm{l}$ dNTPs, $2.5 \mu \mathrm{l} 10$-fold buffer, $2 \mu \mathrm{l}$ Taq polymerase, $0.75 \mu \mathrm{Mgcl}_{2}$ and $14.85 \mu \mathrm{l}$ aqua dest. Thermocycling was performed by denaturation at $94^{\circ} \mathrm{C}$ for $5 \mathrm{~min}$, followed by 30 cycles of $94^{\circ} \mathrm{C}$ for $30 \mathrm{~s}, 56^{\circ} \mathrm{C}$ for $30 \mathrm{~s}$ and $72^{\circ} \mathrm{C}$ for $30 \mathrm{~s}$, and the product of the PCR was analyzed as mentioned above.

\section{Results}

Only the probe that was used as positive control revealed the presence of the $660 \mathrm{bp}$ sequence, but not in the DNA of breast tissues of patients (fig. 1). Similarly, figure 2 reveals the presence of 250 bp sequence was revealed in the ATCC probe only, not in breast tissues (fig. 2).

The stained agarose gels containing the products of PCR of peripheral blood samples are shown in figure 3 and 4. Again, the positive template was 660 and $250 \mathrm{bp}$ sequence-positive, whereas none of the peripheral blood samples were positive for these sequences. Similar results were shown in the normal control group. 


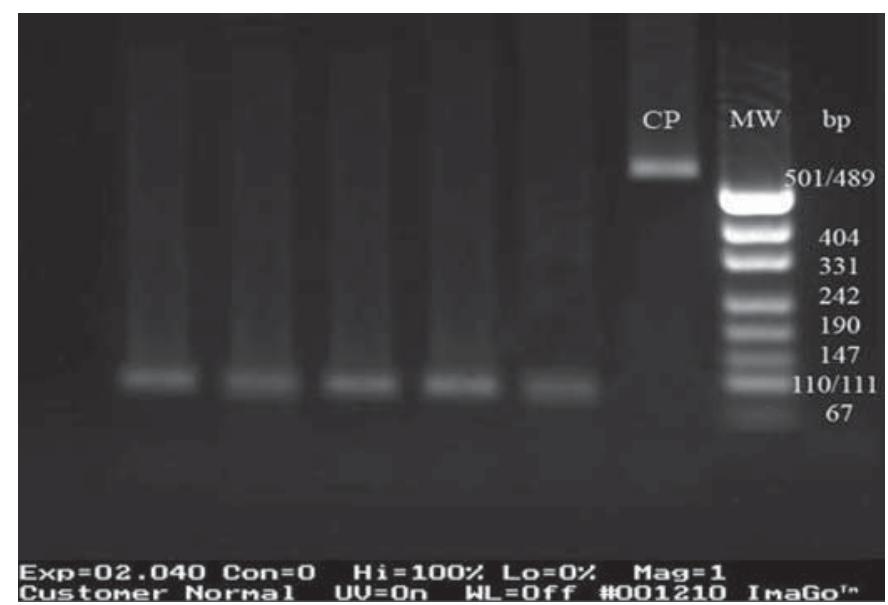

Fig. 1. Image of the ethidium bromide stained gel of the 660 MMTV-like sequence in breast tissues PCR products. CP = Control positive; $\mathrm{MW}=$ molecular weight ladder. $100 \mathrm{bp}$ bands are $\beta$ globin gene fragments as the internal control.

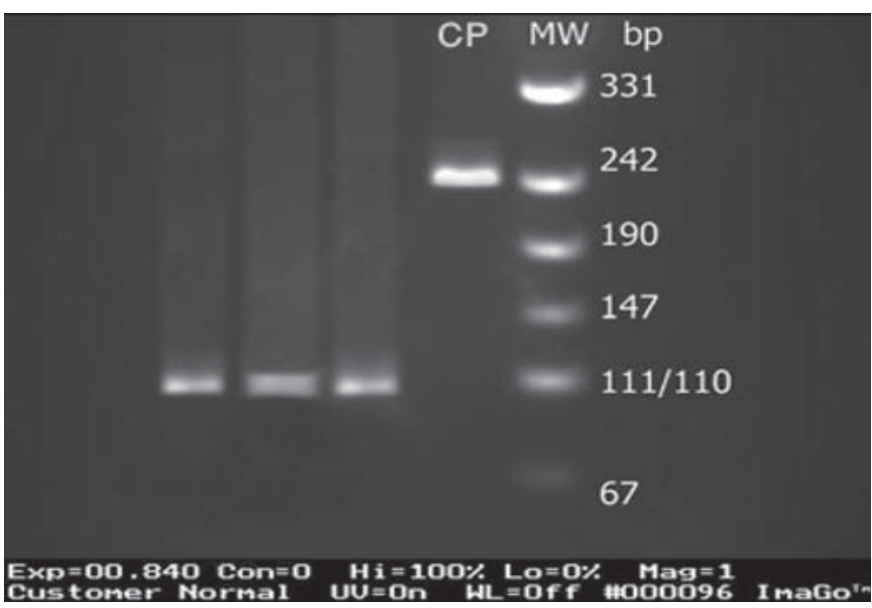

Fig. 2. Image of the ethidium bromide stained gel of the 250 MMTV-like sequence in breast tissues PCR products. CP $=$ Control positive; $\mathrm{MW}=$ molecular weight ladder. $100 \mathrm{bp}$ bands are $\beta$ globin gene fragments as the internal control.

\section{Discussion}

As the etiology of breast cancers remains unknown, it is important to verify observations of diverse breast cancer populations worldwide. Previous studies have purported to disclose an association between MMTV and human breast cancer. Recent reported associations between MMTV or HMTV and human breast cancer have shed new light on the role of MMTV in breast cancer [18].

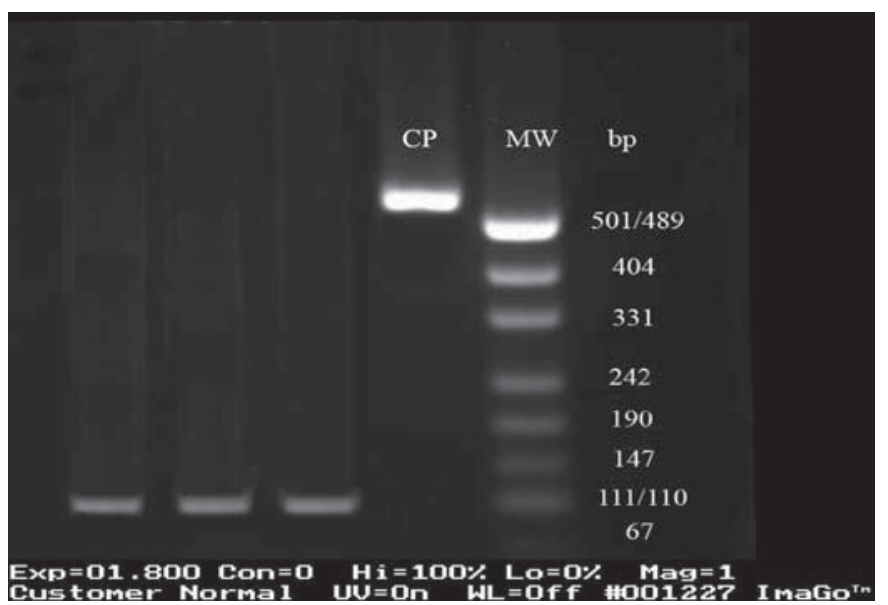

Fig. 3. Image of the ethidium bromide stained gel of the 660 MMTV-like sequence in peripheral blood PCR products. CP = Control positive; $\mathrm{MW}=$ molecular weight ladder. $100 \mathrm{bp}$ bands are $\beta$ globin gene fragments as the internal control.

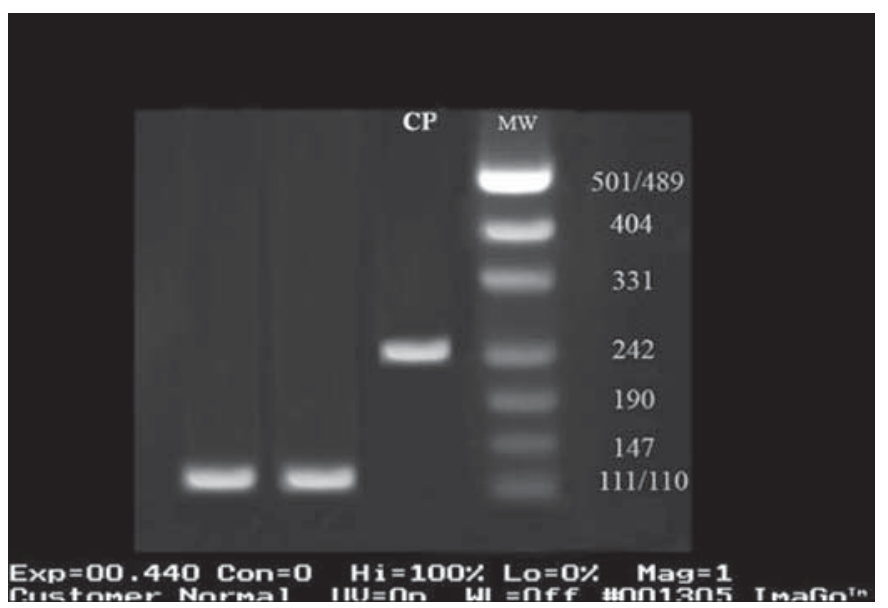

Fig. 4. Image of the ethidium bromide stained gel of the 250 MMTV-like sequence in peripheral blood PCR products. CP = Control positive; $\mathrm{MW}=$ molecular weight ladder. $100 \mathrm{bp}$ bands are $\beta$ globin gene fragments as the internal control.

Our results indicate that $660 \mathrm{bp}$ and $250 \mathrm{bp}$ DNA sequences that are homologous to MMTV env gene sequences are not present in the studied Iranian patients breast tumors and their analyzed blood samples and also in the normal control group. Both the ethnic background and age range of normal populations and breast cancer patients were quite similar.

Many previous studies have shown that MMTV-like sequences are detectable in mammary tissues of women 
with breast cancer $[15,18]$. An investigation by Zapata et al. [19], showed the presence of MMTV-like sequences in Mexican women. In that study, using specific primers for MMTV, 3 breast cancer cell lines and 119 breast cancer samples from Mexican women were tested. MMTV-like gene sequences were amplified in 5 of 119 (4.2\%) breast cancer biopsy tissues but not in cell lines that had been used as a positive breast control in other reports. Evidence from paraffin embedded samples produced supporting data for $37 \%$ of breast cancers from Italy [20, 21]. These data were then highlighted in a study of the prevalence of MMTV DNA PCR positivity in breast cancer patients from Vietnam with $1 \%$ positivity and Australia with $42 \%$ positivity [22]. MMTV-like env sequences have also been detected in human breast samples from women in Australia, Argentina, China, Tunisia and United States [23].

Several of the most recent papers have, however, suggested significantly different interpretations for such discordant experimental findings. For example, Yin et al. [24] were only able to detect MMTV-like virus by PCR in one ( $\sim 2 \%)$ of 60 breast cancers and, in a careful quantitative PCR study of 17 ductal carcinomas, tested in 7 different MMTV PCRs, none produced a positive PCR reaction [25]. Similarly, a laboratory was able to detect PCR amplicons of the expected size in $16 \%$ of 44 breast cancer patients but, upon DNA sequencing, all 110 DNA sequences turned out to be false positive, comprising host genomic DNA [26]. In a study in Sweden using a sensitive real-time PCR method, none of the blood leukocyte samples, cancer samples and controls were reported to indicate 1-10 copies of MMTV target DNA, and it was concluded that previous reports on MMTV in human breast cancers may have been due to unspecific (e.g. due to plasmid or amplimer contamination) PCR amplification [27]. Also in a recent report, no MMTV sequences were found in 42 specimens in tumor-enriched DNA using a sensitive test based on strong $\beta$ globin nested PCR [28]. However Pogo et al. criticized that report, as the methodology was unable to amplify low copies of MMTV sequences. They claimed that their methods were based on a report by Wang et al. [14], which could show that one copy of plasmid containing $660 \mathrm{bp}$ of MMTV-like env sequences was more sensitive [29].

In light of our finding, one might conclude that the methodology and sample sizes herein were not capable of detecting MMTV-like env gene sequences with low homology to HERVs in the 50 samples of Iranian breast cancer DNA. By using a sensitive PCR [29], we were unable to detect the MMTV-like sequences in blood DNA sam- ples of 300 Iranian breast cancer patients. Therefore, the discrepancy between previous studies and the present study may arise from differing geographic distribution of etiologic agents, vectors, or clustering of populations with different infection of cancer susceptibilities, or may result from different MMTV diagnostic methods. The prevalence of MMTV in both feral mice and human breast cancer varies greatly between populations. Stewart et al. [30] proposed a zoonotic theory for MMTV as a viral cause of human breast cancer and suggested that the highest incidence of such cancers occurs in regions where Mus domesticus is the prevalent mouse species. However, some studies of Australian, Japanese and Chinese women revealed no association between MMTV or MMTV-related retrovirus and breast carcinogenesis [28, 29]. The absence of MMTV DNA in both breast cancer samples and controls indicates either that the concentration of putative MMTV or HMTV DNA in the breast cancers was too low for detection or that it did not exist there. It also suggests that MMTV-like viral expression in humans may be influenced by hormones $[15,23]$.

\section{Conclusion}

MMTV-like sequences were not detected in Iranian patients in Shiraz with breast cancer. We therefore recommend that probable association between MMTV-like sequences with development of breast cancer be interpreted with caution.

\section{Acknowledgments}

This study was related to the MSc thesis of Mr. Morteza Saki and was supported financially by Shiraz Institute for Cancer Research grant No. ICR-87-501 and Shiraz University of Medical Sciences grant No. 2867. Also thanks to Dr. A.A. Gorzin for preliminary provision of MMTV constructs.

References

\footnotetext{
1 Pagano JS, Blaser M, Buendia MA, Damania B, Khalili K, Raab-Traub, N, Roizman B: Infectious agents and cancer: criteria for a causal relation. Semin Cancer Biol 2004;14: 453-471.

2 Moore DH, Long CA, Vaidya AB, Sheffield JB, Dion AS, Lasfargues EY: Mammary tumor virus. Adv Cancer Res 1979;29:347-415.

-3 Bittner J: The milk influence of breast tumor in mice. Science 1942;95:462-463.
} 
4 Levine P, Mourali N, Tabbave F, Costa J, Mesa-Tejada R, Spiegelman S, Muenz R, Bekesi YG: Immunopathologic features of rapidly processing breast cancer (RPBC) in Tunisia. Proc Am Assoc Cancer Res 1980;21:170.

$\checkmark 5$ Lloyd R, Rosen PP, Sarkar NH, Jimenez D, Kinne DW, Mendez-Botet C, Schwartz MK: Murine mammary tumor virus related antigen in human male mammary carcinoma. Cancer 1983;51:654-661.

-6 Litvinov SV, Golovkina TV: Expression of proteins immunologically related to murine mammary tumor virus (MMTV) core proteins in the cells of breast cancer continuous lines MCF-7, T47D, MDA-231, and cells from human milk. Acta Virol 1989;33:137-142.

-7 Zotter S, Kemmer C, Lossnitzer A, Grossmann $\mathrm{H}$, Johannsen BA: Mouse mammary tumor virus-related antigens in core-like density fractions from large samples of women's milk. Eur J Cancer 1980;16:455-467.

$\checkmark 8$ Day NK, Witkin SS, Sarkar NH, Kinne D, Jussawalla DJ, Levin A, Hsia CC, Geller N, Good RA: Antibodies reactive with murine mammary tumor virus in sera of patients with breast cancer: geographic and family studies. Proc Natl Acad Sci USA 1981;78: 2483-2487.

-9 Witkin SS, Sarkar NH, Kinne DW, Breed CN, Good RA, Day NK: Antigens and antibodies cross-reactive to the murine mammary tumor virus in human breast cyst fluids. J Clin Investig 1981;67:216-222.

-10 Keydar L, Ohno T, Nayak R, Sweet R, Simoni F, Weiss F, Karby S, Mesa-Tejada R, Spiegelman S: Properties of retrovirus-like particles produced by a human breast carcinoma cell line: immunological relationship with mouse mammary tumor virus proteins. Proc Natl Acad Sci USA 1984;81:4188-4192.

-11 Axel R, Schlom J, Spiegelman S: Presence in human breast cancer of RNA homologous to mouse mammary tumor virus RNA. Nature 1972;235:32-36.

12 Westley B, May FE: The human genome contains multiple sequences of varying homology to mouse mammary tumor-virus DNA. Gene 1984;28:221-227.
13 Ono M, Yasunaga T, Miyata T, Shikubo H: Nucleotide sequence of human endogenous retrovirus genome related to the mouse mammary tumor virus genome. J Virol 1986; 60:589-598.

14 Wang Y, Holland JF, Bleiweiss IJ, Melana S, Liu X, Pelisson I, Cantarella A, Stellrecht K, Mani S, Pogo BG: Detection of mammary tumor virus ENV gene-like sequences in human breast cancer. Cancer Res 1995;55: 5173-5179.

15 Pogo BG, Holland JF, Levine PH: Human mammary tumor virus in inflammatory breast cancer. Cancer 2010;116(11 suppl): 2741-2744.

-16 Saiki RK, Bugawan TL, Horn GT, Mullis KB, Erlich HA: Analysis of enzymatically amplified beta-globin and HLA-DQ alpha DNA with allele-specific oligonucleotide probes. Nature 1986;324:163-166.

17 Etkind P, Du J, Khan A, Pillitri J, Wiernik PH: Mouse mammary tumor virus like env gene sequence in human breast tumors and in a lymphoma of a breast cancer patient. Clin Cancer Res 2000;6:1273-1278.

18 Etkind PR, Stewart AFR, Wiernik PH: Mouse mammary tumor virus (MMTV)like DNA sequences in the breast tumors of father, mother, and daughter. Infect Agent Cancer 2008;3:2.

19 Zapata Benavides P, Saavedra Alonso S, Zamora Avila D, Vargas Rodarte C, Barrera Rodríguez R, Salinas Silva J, Rodríguez Padilla C, Tamez Guerra R, Trejo Avila L: Mouse mammary tumor virus-like gene sequences in breast cancer samples of Mexican women. Intervirology 2007;50:402-407.

20 Pogo BG, Melana SM, Holland JF, Mandeli JF, Pilotti S, Casalini P, Ménard S: Sequences homologous to the mouse mammary tumor virus env gene in human breast carcinoma correlate with overexpression of laminin receptor. Clin Cancer Res 1999;5:2108-2111.

21 Zammarchi F, Pistello M, Piersigilli A, Murr R, Di Cristofano C, Naccarato AG, Bevilacqua G: MMTV-like sequences in human breast cancer: a fluorescent PCR/laser microdissection approach. J Pathol 2006;209: 436-444.
22 Ford CE, Tran D, Deng Y, Ta VT, Rawlinson WD, Lawson JS: Mouse mammary tumorlike gene sequences in breast tumors of Australian and Vietnamese women. Clin Cancer Res 2003;9:1118-1120.

23 Lawson JS, Glenn WK, Salmons B, Ye Y, Heng B, Moody P, Johal H, Rawlinson WD, Delprado W, Lutze-Mann L, Whitaker NJ: Mouse mammary tumor virus-like sequences in human breast cancer. Cancer Res 2010; 70:3576-3585.

24 Yin $\mathrm{H}$, Medstrand ML, Borg A, Olsson H, Blomberg J: Transcription of human endogenous retroviral sequences related to mouse mammary tumor virus in human breast and placenta: similar pattern in most malignant and non malignant breast tissues. AIDS Res Hum Retroviruses 1997;13:507-516.

25 Ting CN, Rosenberg MP, Snow CM, Samuelson LC, Meisler MH: Endogenous retroviral sequences are required for tissue specific expression of the salivary amylase gene. Genes Dev 1992;6:1457-1465.

26 Mant C, Cason J: Human murine mammary tumour virus like agent is an unconvincing aetiological agent for human breast cancer. Rev Med Virol 2004;14:169-177.

27 Bindra A, Muradrasoli S, Kisekka R, Nordgren $\mathrm{H}$, Wärnberg F, Blomberg J: Search for DNA of exogenous mouse mammary tumor virus-related virus in human breast cancer samples. J Gen Virol 2007;88:1806-1809.

-28 Park DJ, Southey MC, Giles GG, Hopper JL: No evidence of MMTV-like env sequences in specimens from the Australian Breast Cancer Family Study. Breast Cancer Res Treat 2011;125:229-235.

29 Pogo BG, Melana SM, Moran H, Holland JF: Presence of MMTV-like env gene sequences in human breast cancer. Breast Cancer Res Treat 2011;125:295-297.

30 Stewart TH, Sage RD, Stewart AF, Cameron DW: Breast cancer incidence highest in the range of one species of house mouse, Mus domesticus. Br J Cancer 2000;82:446-451. 